\title{
O SISTEMA INTERAMERICANO DE PROTEÇ̃̃O AOS DIREITOS HUMANOS E O CASO DO CONDOMÍNIO BARÃ̃O DE MAUÁ: A EFETIVIDADE DOS DIREITOS HUMANOS FRENTE AOS INTERESSES DAS EMPRESAS TRANSNACIONAIS
}

\author{
THE PROTECTION INTER-AMERICAN SYSTEM FOR HUMAN RIGHTS \\ AND THE CASE OF CONDOMÍNIO BARÃO DE MAUÁ: THE \\ EFFECTIVENESS OF HUMAN RIGHTS FRONT TO INTERESTS OF \\ TRANSNATIONAL CORPORATIONS
}

\author{
${ }^{1}$ Lucilo Perondi Junior
}

\section{RESUMO}

Este trabalho tem o objetivo de analisar o caso do Condomínio Barão de Mauá, no qual o Brasil foi denunciado perante a Comissão Interamericana de Direitos Humanos. Para tanto se examinará o sistema interamericano de proteção dos direitos humanos, bem como o importante papel desenvolvido pela Comissão. Ainda se analisará o próprio sistema interamericano de direitos humanos, as responsabilidades do Estado Brasileiro frente ao não cumprimento dos Direitos Humanos. Examina-se ainda a decisão da Comissão que entendeu admissível a denúncia em face do Brasil, pelo caso do Condomínio Barão de Mauá, e a violação a diversos artigos da Convenção Americana.

Palavras-chave: Direitos humanos, Sistema interamericano de proteção aos direitos humanos, Caso barão de mauá

\begin{abstract}
This work aims to analyze the case of the "Condominium Baron of Mauá", in which Brazil was denounced before the Inter-American Commission on Human Rights. For that it examines the inter-American system of human rights protection as well as the important role played by the Commission. Still consider himself inter-American human rights system, the Brazilian state responsibilities against the non-fulfillment of human rights. It also examines the decision of the Commission understood the complaint admissible in view of Brazil, by the case of "Condominium Baron of Mauá" and the violation of several articles of the American Convention.
\end{abstract}

Keywords: Human rights, Inter-american system for the protection of human rights, Caso barão de mauá

\footnotetext{
${ }^{1}$ Mestrando em Direito Área de Concentração: Justiça, Empresa e Sustentabilidade pela Universidade Nove de Julho - UNINOVE, São Paulo, Brasil. Professor da Universidade Nove de Julho - UNINOVE, Brasil. E-mail: tutortreinamento@gmail.com
} 


\section{INTRODUÇÃO}

A importância e o valor dos direitos humanos na sociedade moderna e a intervenção regular dos tratados e instrumentos internacionais de direitos humanos têm demonstrado, de forma indiscutível, que podem beneficiar diretamente os indivíduos, assegurando a dignidade da pessoa humana, que se beneficia de garantias internacionais institucionalizadas.

O Sistema Interamericano de Direitos Humanos merece relevo nesse cenário, tendo em vista a sua incidência no processo de internacionalização dos sistemas jurídicos de diversos países da América Latina.

A Corte Interamericana de Direitos Humanos passou a julgar vários casos de violações de direitos humanos, o que tem contribuído para importantes mudanças institucionais no âmbito dos sistemas de justiça nacionais.

Indiscutível que a proteção dos direitos humanos, tomou uma nova força quando sua positivação alcançou as fronteiras internacionais, aumentando a importância de muitos órgãos criados por seus membros para justamente julgar abusos contra esse tipo de direito.

$\mathrm{Na}$ realidade se verifica, juntamente com os efeitos da globalização, uma internacionalização do Direito e nesta esteira, a preocupação dos Estados com esse fenômeno quando o assunto é a proteção aos direitos humanos.

Neste sentido, em razão dessa ação, nascem diversas e inúmeras convenções de caráter internacional que visam justamente garantir o bem-estar mínimo do ser humano, tendo como instrumento mais conhecido a Declaração dos Direitos do Homem, assinada em 10 de dezembro de 1948 no âmbito da Assembléia Geral das Nações Unidas.

Considerando a importância desse documento, após sua assinatura, a proteção aos direitos humanos tomou uma ordem de grandeza maior com relação aos assuntos internos dos Estados, já que se verifica uma preocupação como toda a humanidade, de forma geral.

A partir da assinatura dessa Declaração, a proteção dos direitos humanos passaria a ser considerada não mais como assunto interno de cada Estado, mas como foco do interesse comum de toda humanidade (COMPARATO, 2003, p. 54).

Tanto a ampliação e preocupação dos Estados pelos direitos humanos, como o surgimento de diversos documentos voltados a garanti-los, se tratam de fenômenos que ajudam com o nascimento de diversos Sistemas Jurídicos Internacionais, voltados justamente para a proteção dos direitos humanos.

Temos aí, os chamados Sistemas Regionais de Proteção, dentre eles o Europeu, o 
Americano e o Africano, nascendo assim o que se pode denominar de Direito Internacional dos Direitos Humanos.

A Constituição Federal de 1988 é de suma importância na preocupação do Brasil com a proteção dos direitos humanos, já que além de se preocupar com tal questão, também deu ênfase a princípios de relações internacionais, importantes para se estreitar a internacionalização efetiva destas proteções.

Não se pode ainda deixar de mencionar que a proteção dos direitos humanos no Brasil, também se mostrou mais dinâmico em razão de sua adesão à Convenção Americana de Direitos Humanos, bem como a sua submissão à Comissão Interamericana de Direitos Humanos e da Corte Interamericana de Direitos Humanos, dando mais uma opção de ajuda para àqueles que vêm seu direito não respeitado pelo Estado Brasileiro.

Sendo assim, no presente estudo se analisará o Caso do Condomínio "Barão de Mauá", no qual o Brasil foi denunciado a Comissão Interamericana de Direitos Humanos e posteriormente submetido a jurisdição internacional da Corte Interamericana de Direitos Humanos.

Cuida-se aqui em analisar o Sistema Interamericano de Direitos Humanos, descrever os desdobramentos do caso até o presente momento diante da Corte, bem como avaliar o descaso do Estado Brasileiro no respeito aos aspectos mais basilares da humanidade, tutelados de forma significativa pelos Direitos Humanos.

\section{DO SISTEMA INTERAMERICANO DE PROTEÇÃO AOS DIREITOS HUMANOS}

As intenções internacionais de proteção aos direitos humanos, no continente americano, culminaram na proposição pela OEA - Organização dos Estados Americanos, no ano de 1948, da Carta da Organização dos Estados Americanos, onde fora aprovada a Declaração Americana de Direitos e Deveres do Homem.

A referida declaração foi o primeiro grande instrumento de relevância internacional no campo da proteção internacional dos direitos humanos, já que aprovada 10 meses antes daquela firmada na Assembléia das Nações Unidas.

Neste aspecto, continuando essa tendência mundial em se amparar os direitos humanos, em 1959, cria-se a Comissão Interamericana dos Direitos Humanos, órgão responsável a examinar as reclamações de indivíduos contra violações a direitos humanos ocorridas nos Estados-membros.

Em 22 de novembro de 1969 foi finalmente adotada a Convenção Americana sobre 
Direitos Humanos, também conhecido como Pacto de São José da Costa Rica.

A Convenção Americana sobre Direitos Humanos, disciplina juridicamente os deveres dos Estados-membros, da organização e estrutura do Sistema Interamericano de Proteção dos Direitos Humanos.

A Convenção entrou em vigor em 1978, após alcançar o mínimo de onze ratificações, e, no ano seguinte, na mesma cidade de São José da Costa Rica, foi fundada a Corte Interamericana de Direitos Humanos.

O Sistema Interamericano de Proteção dos Direitos Humanos baseia-se, fundamentalmente, no trabalho de dois órgãos: a Comissão Interamericana de Direitos Humanos e a Corte Interamericana de Direitos Humanos, sendo considerado, portanto, um sistema bifásico de proteção aos direitos humanos.

Ambos os órgãos não são permanentes, já que se reúnem em períodos prédeterminados, em sessões anuais. A Comissão Interamericana de Direitos Humanos tem como objetivo principal promover a observação e a defesa dos direitos humanos, atuando ao mesmo tempo como órgão de consulta da OEA nesta matéria, sendo que representa todos os países que compõem a OEA.

A Comissão Interamericana possui sete membros, eleitos a título pessoal pela Assembléia Geral da OEA, por um período de quatro anos, com possibilidade de uma reeleição.

A sede da Comissão Interamericana de Direitos Humanos é na cidade de Washington, Estados Unidos, onde funciona permanentemente sua Secretaria Executiva, unidade administrativa especializada, encarregada de cumprir as tarefas que lhe são confiadas pela Comissão. Essa unidade administrativa especializada está a cargo de um secretário executivo, nomeado pelo secretário geral da OEA, em consulta com a Comissão.

As funções da Comissão Interamericana de Direitos Humanos são: estimular a consciência dos direitos humanos nos povos da América; velar pela observância e pelo respeito desses direitos nos Estados americanos; tramitar petições de vítimas de violações aos direitos humanos (ou de seus representantes) que, tendo sem êxito utilizado os recursos legais internos, apresentam denúncias contra algum dos Estados membros do Sistema Interamericano e estimular a consciência dos direitos humanos nos povos da América.

A Comissão é o primeiro órgão a tomar conhecimento de uma denúncia individual, e só em uma segunda etapa, a própria Comissão poderá levar a denúncia perante a Corte.

Já a Corte Interamericana de Direitos Humanos tem sua seda em São José da Costa Rica, é um órgão judicial internacional autônomo do sistema da OEA, sendo criada pela 
Convenção Americana dos Direitos do Homem, tendo por competência o caráter tanto contencioso, como consultivo.

Consiste em um tribunal composto por sete juízes nacionais dos Estados-membros da OEA, eleitos, a título pessoal, entre juristas da mais alta autoridade moral, de reconhecido saber jurídico em matéria de direitos humanos, os quais reúnam as condições requeridas para o exercício das mais elevadas funções judiciais, de acordo com a lei do Estado do qual sejam nacionais (art. 52 da Convenção Interamericana).

A Corte Interamericana de Direitos Humanos tem competência para conhecer de qualquer caso relativo à interpretação e aplicação das disposições da Convenção Americana sobre Direitos humanos, desde que os Estados Partes, no caso tenham reconhecido a sua competência. Somente a Comissão Interamericana e os Estados Partes da Convenção Americana sobre Direitos Humanos podem submeter um caso à decisão desse Tribunal.

No exercício de sua competência consultiva, a Corte Interamericana tem desenvolvido análises elucidativas a respeito do alcance e do impacto dos dispositivos da Convenção Americana, emitindo opiniões que têm facilitado a compreensão de aspectos substanciais da Convenção, contribuindo para a construção e evolução do Direito Internacional dos Direitos Humanos no âmbito da America Latina.

No plano contencioso, sua competência para o julgamento de casos, limitada aos Estados Partes da Convenção que tenham expressamente reconhecido sua jurisdição, consiste na apreciação de questões envolvendo denúncia de violação, por qualquer Estado Parte, de direito protegido pela Convenção. Caso reconheça que efetivamente ocorreu a violação à Convenção, determinará a adoção de medidas que se façam necessárias à restauração do direito então violado, podendo condenar o Estado, inclusive, ao pagamento de uma justa compensação à vítima.

Somente a Comissão e os Estados-Partes da OEA têm legitimidade para a apresentação de demandas perante a Corte. Desse modo, qualquer indivíduo que pretenda submeter denúncia à apreciação da Corte, deve, necessariamente, apresentá-la à Comissão Interamericana.

A partir do ano de 1996, todavia, inovação trazida pelo III Regulamento da Corte Interamericana de Direitos Humanos ampliou a possibilidade de participação do indivíduo no processo, autorizando que os representantes ou familiares das vítimas apresentassem, de forma autônoma, suas próprias alegações e provas durante a etapa de discussão sobre as reparações devidas. 
Além disso, hoje, com as alterações trazidas pelo IV Regulamento, também é possível que as vítimas, seus representantes e familiares não só ofereçam suas próprias peças de argumentação e provas em todas as etapas do procedimento, como também façam uso da palavra durante as audiências públicas celebradas, ostentando, assim, a condição de verdadeiras partes no processo.

O Brasil somente reconheceu a jurisdição contenciosa da Corte em 10 de dezembro de 1998, assim, só podem ser apresentadas a ela denúncias de violações ocorridas após essa data. Porém, a Comissão pode receber denúncias de violações anteriores, isso porque sua competência se estende à análise de violações da Declaração Americana 62 (1948) e da Convenção Americana desde a ratificação pelo Brasil em 1992.

\section{O BRASIL E A RESPONSABILIDADE INTERNACIONAL POR VIOLAÇÃO DE DIREITOS HUMANOS}

Apesar dos ordenamentos constitucionais brasileiros fazerem referência a tratados internacionais desde 1824 na Carta do Império (art. 102, VIII), o Brasil passa a ratificar os principais tratados de proteção dos direitos humanos apenas com o processo de democratização, iniciado em 1985. Com a Constituição de 1988, que consagra os princípios da prevalência dos direitos humanos e da dignidade humana, o Brasil começa a se inserir no cenário de proteção internacional dos direitos humanos.

Sustenta o Ministro do Supremo Tribunal Federal, Gilmar Ferreira Mendes ${ }^{1}$, sobre os direitos fundamentais e a ordem constitucional brasileira, que:

\footnotetext{
A Constituição brasileira de 1988 atribuiu significado ímpar aos direitos individuais. Já a colocação do catálogo dos direitos fundamentais no início do texto constitucional denota a intenção do constituinte de lhes emprestar significado especial. A amplitude conferida ao texto, que se desdobra em setenta e sete incisos e dois parágrafos (art. 5o), reforça a impressão sobre a posição de destaque que o constituinte quis outorgar a esses direitos. A ideia de que os direitos individuais devem ter eficácia imediata ressalta a vinculação direta dos órgãos estatais a esses direitos e o seu dever de guardar-lhes estrita observância.
}

${ }^{7}$ MENDES, Gilmar. Os direitos fundamentais e seus múltiplos significados na ordem constitucional. Revista Diálogo Jurídico, Salvador, CAJ - Centro de Atualização Jurídica, nº ${ }^{\circ}$ 10, janeiro, 2002. Disponível na Internet: <http://www.direitopublico.com.br>. Acesso em: 31/05/2015 
Desde 2004, após a Emenda Constitucional nº 45/04, conforme mandamento do $\S 3^{\circ}$, do artigo $5^{\circ}$, da Constituição Federal de 1988, os tratados internacionais assinados pelo Brasil que versem sobre direitos humanos e que sejam aprovados em cada Casa do Congresso Nacional, em dois turnos, por três quintos dos votos dos respectivos membros, são equivalentes a uma emenda constitucional.

Os tratados de direitos humanos se incorporam no Direito interno brasileiro: (a) como Emenda Constitucional (CF, art. 5. $.^{\circ} \S 3 .^{\circ}$ ) ou (b) como Direito supralegal (voto do Min. Gilmar Mendes, que não chegou a concebê-los como normas constitucionais) ou (c) como Direito constitucional $\left(\mathrm{CF}\right.$, art. $\left.5 .^{\circ}, \S 2 .^{\circ}\right)$.

\title{
Aponta Valério de Oliveira Mazzuoli²:
}

\begin{abstract}
Aspecto que não pode ser esquecido é o de que os tratados internacionais por nós ratificados passam a incorporar-se automaticamente em nosso ordenamento, pelo que estatui o $\S 1^{\circ}$. do Art. $5^{\circ}$ da nossa Carta: "As norma definidoras dos direitos e garantias fundamentais têm aplicação imediata”. Ora, se as normas definidoras dos direitos e garantias fundamentais têm aplicação imediata, os tratados internacionais de direitos humanos, uma vez ratificados, por também conterem normas que dispõe sobre direitos e garantias fundamentais, terão, dentro do contexto constitucional brasileiro, idêntica aplicação imediata.
\end{abstract}

Com relação aos tratados internacionais anteriores a EC 45/2004 há um conflito de interpretação. Para George Marmelstein³:

\begin{abstract}
Ainda não há uma resposta definitiva do STF, mas duas tendências podem ser observadas. A primeira, defendida por Gilmar Mendes, sustenta que os tratados internacionais de direitos humanos subscritos pelo Brasil passariam ter um status normativo supralegal, tornando inaplicável a legislação infraconstitucional com eles conflitantes, seja ela anterior ou posterior ao ato de ratificação. A segunda, defendida por Celso Mello, sustenta que os tratados internacionais de direitos humanos já incorporados ao direito brasileiro fórum recepcionados com o status constitucional, conforme defendia Flavia Piovesan.
\end{abstract}

Porém, no caso dos direitos humanos especificamente, os tratados internacionais têm como foco principal proteger a "dignidade humana", ou seja, deve-se levar em conta sempre a

\footnotetext{
${ }^{8}$ Direitos Humanos \& Relações Internacionais, p.109/110

${ }^{3}$ Curso de Direitos Fundamentais, $3^{\mathrm{a}}$ ed. São Paulo: Editora Atlas. 2011.
} 
norma que melhor favoreça a pessoa humana, conforme sustentam muitos doutrinadores.

Segundo esclarece Antonio Augusto Cançado Trindade ${ }^{4}$ :

No presente domínio de proteção, não mais há pretensão de primazia do direito internacional ou do direito interno, como ocorria na polêmica clássica e superada entre monistas e dualistas. No presente contexto, a primazia é da norma mais favorável às vítimas, que melhor as proteja, seja ela de direito internacional ou de direito interno. É a solução expressamente consagrada em diversos tratados de direitos humanos, da maior relevância por suas implicações práticas.

Sustenta Valério de Oliveira Mazzuoli ${ }^{5}$ que:

[...], ingressando tais tratados no ordenamento jurídico interno como norma constitucional $\left(\mathrm{CF}\right.$, art., $\left.\S 2^{\circ}\right)$, a aparente contradição entre essas "duas normas constitucionais" conflitantes deve ser resolvida dando sempre prevalência ao interesse (valor) maior em conflito. Com vimos, sempre que uma norma proveniente de tratados internacionais, contiver disposições de direito que favoreça o ser humano, esta norma, como tal, passa a ser considerada, por permissão expressa da própria Carta Magna, verdadeira “norma constitucional”. E, se por ventura, houver choque entre esta nova norma incorporada por um tratado e alguma disposição constitucional, ou seja, se houver contraposição entre estas "duas normas constitucionais", (que são, logo. Da mesma categoria), terá primazia a norma que der prevalência aos direitos humanos, consoante dispõe o art. 4, II da Constituição Federal, [...].

Importante destacar a necessidade da participação da sociedade civil na defesa e proteção dos direitos humanos no Brasil, propondo tanto no âmbito interno, como no internacional, ações perante os órgãos do sistema global e regional de proteção dos direitos humanos, pois, os instrumentos internacionais constituem um poderoso aliado para reforçar a proteção dos direitos humanos e o regime democrático no país.

Também é de grande importância o entendimento dos Estados na responsabilidade que lhes cabe, quando signatários de tratados internacionais, pois se torna obrigatório o cumprimento das decisões proferidas pelas Cortes Internacionais, como se depreende:

\footnotetext{
${ }^{4}$ Tratado de Direito Internacional dos Direitos Humanos, vol I.

${ }^{5}$ Curso de Direitos Fundamentais, p. 231, P. 434.
} 
Reconhecida a jurisdição internacional da Corte, os países signatários do tratado são obrigados a respeitar e cumprir as decisões proferidas pelo órgão internacional, não autorizado, sequer, a alegação de ausência de meios internos para se cumprimento, sob pena de nova infração internacional. ${ }^{6}$

Flávia Piovesan ${ }^{7}$ entende que:

A experiência brasileira revela que a ação internacional tem também auxiliado a publicidade das violações de direitos humanos, o que oferece o risco do constrangimento político e moral ao Estado violador, e, nesse sentido, surge como significativo fator para a proteção dos direitos humanos. Ademais, ao enfrentar a publicidade das violações de direitos humanos, bem como as pressões internacionais, o Estado é praticamente "compelido" a apresentar justificativas a respeito de sua prática.

Desta feita, se verifica que o Estado brasileiro tenta organizar seu sistema de proteção internacional dos Direitos Humanos, incorporando ao seu ordenamento jurídico mecanismos mais amplos e eficazes no combate aos desrespeitos aos direitos básicos do ser humano, o que muitas vezes culmina em sua condenação nos órgãos internacionais, como é o caso da Corte Interamericana de Direitos Humanos.

\section{O CASO DO CONDOMINIO BARÃO DE MAUÁ}

O "Condomínio Barão de Mauá” se trata de um loteamento e conjunto habitacional localizado na cidade de Mauá, município localizado na Grande São Paulo, o qual tem caráter essencialmente residencial.

Trata-se de uma grande área construída com aproximadamente 160.000 mil metros quadrados, localizado exatamente no Parque São Vicente, cidade de Mauá, na grande São Paulo, onde se levantaram 72 blocos de edifícios de apartamentos com oito em cada andar, chegando ao número de 2.304 unidades autônomas com área cada uma, de aproximadamente 64 metros quadrado.

Sua implementação jurídica e comercialização se deu pela empresa Paulicoop Planejamento e Assessoria a Cooperativas Habitacionais S/C Ltda.

\footnotetext{
${ }^{6}$ In: A Convivência Pacífica entre Decisões Internas e Internacionais: Corte Interamericana de Direitos Humanos. Peres, V.M.S Martins e Peres, A. Martins, p. 328.

${ }^{7}$ Direitos Humanos e o Direito Constitucional Internacional, p. 313
} 
Residiam, na época dos fatos que ensejaram a denúncia perante a Corte Interamericana de Direitos humanos, aproximadamente 1.760 famílias e mais de 5.000 pessoas.

Grande parte dessa área se trata de uma região completamente contaminada por compostos orgânicos e inorgânicos, alguns deles voláteis, como por exemplo o benzeno, clorobenzeno e o decano.

O "Condomínio Conjunto Residencial Barão de Mauá” foi implantado em um terreno pertencente a empresa de amortecedores COFAP, a qual utilizou toda a área como aterro de resíduos sólidos industrial antes de sua venda para o início da construção do condomínio residencial.

Na época, não havia qualquer tipo de controle da área pelos proprietários, ocasionando a utilização do terreno também para depósito de outras substâncias tóxicas, de origem desconhecida, que ali foram depositadas inadequadamente durante anos.

Foi verificado que nem todos os edifícios existentes no condomínio foram implantados no terreno que sofre contaminação, mas muitas áreas de convivência comum do condomínio, como por exemplo, estacionamento, playground, portaria e outras instalações, estavam condenadas pela contaminação do descarte indevido de produtos tóxicos.

Ocorre que no dia 20 de abril de 2000, houve uma grande explosão dentro do condomínio, provocando um incêndio. Na ocasião houve duas vítimas, inclusive uma delas fatal.

Em tal incidente, o qual ocorreu quando já haviam moradores no Condomínio, a contaminação produziu a explosão de um dos tanques subterrâneos, causando a morte de um dos trabalhadores da construção, Geraldo Júlio Rivielo, e grave lesão corporal em outro, Marco Vinicius Lazari Ferreira, que sofreu queimaduras de $25 \%$ do corpo.

A partir desse evento, os moradores começaram a suspeitar que houvesse algo de errado com o terreno em que o condomínio estava construído. O mau odor exalado, as dores de cabeças e náuseas comuns e constantes nos moradores do condomínio associados ao incidente da explosão, foram suficientes para a desconfiança de que o terreno onde está construído o condomínio tinha problemas de contaminação de gases tóxicos graves.

Um laudo técnico após tais fatos fora elaborado na época pela CETESB-Companhia Ambiental do Estado de São Paulo, a qual é responsável pelo controle, fiscalização, monitoramento e licenciamento de atividades geradoras de poluição.

Abaixo transcrição de parte do laudo técnico feito pela CETESB $^{8}$ :

\footnotetext{
${ }^{8}$ CETESB - Companhia de Tecnologia de Saneamento Ambiental- Informação Técnica no 028/00/EERO:
} 
Que os blocos de apartamentos foram edificados sobre um antigo local de deposição de resíduos industriais e domiciliares da região, condição propícia para a formação no subsolo de biogás, cujo principal componente é o gás metano (inflamável). Ressalta-se que normalmente em tais condições os gases gerados no subsolo podem atingir pressões tais que permitam seu afloramento à superfície do solo.

Após tal episódio, chegou-se a informação de que toda a área então adquirida em 1974 pela COFAP e que tinha sido construído o condomínio, foi utilizada com o aval da empresa, como deposito de lixo industrial e doméstico diretamente no solo sem qualquer tratamento, por meio de aterro, o que ocasionou a contaminação do terreno.

Entretanto, não se verifica negligência apenas da primeira proprietária do terreno, já que 1996 a titularidade do terreno passa para a Cooperativa Habitacional Nosso Teto, envolvida diretamente no loteamento, construção e venda das unidades habitacionais aos seus moradores.

Importante destacar que antes do início das obras para construção do condomínio Barão de Mauá houve a elaboração de um memorial descritivo feito pela Administradora e Construtora Soma Ltda., subscrita pela COFAP e Cooperativa Habitacional Nosso Teto, não mencionava qualquer situação de contaminação na área a ser construída.

Destaque-se ainda que o próprio Poder Público se quedou inerte a tal situação, pois a Prefeitura Municipal de Mauá concedeu sem qualquer contestação "Alvará de Construção”, aprovando toda a documentação apresentada pelos responsáveis para que se iniciasse a construção do condomínio residencial.

Ainda, tem-se que a empresa SQG Empreendimentos e Construções, a qual assumiu a obra posteriormente junto a Paulicoop, encaminhou ofício à municipalidade de Mauá no seguinte sentido:

Após a análise das folhas ns. SPO 075,0693-A, 0693,0682 E 0725 da empresa Omega Geologia e Geotecnia, relativas ás sondagens do empreendimento em questão, verifica-se a inexistência de materiais nocivos á saúde.

Assim ficou evidenciado que o terreno onde fora construído o Condomínio Barão de Mauá, estava completamente contaminado dos mais variados gases tóxicos, sendo sua em sua grane maioria nocivos para a saúde humana.

$\mathrm{Na}$ realidade em laudos técnicos realizados posteriormente foram encontrados a ação de mais de 44 diferentes compostos orgânicos, sendo após estudos, constatado a existência de 
um gigantesco aterro nos domínios da construção do Condomínio Barão de Mauá, com aproximadamente 33 mil metros quadrados, contendo plásticos diversos, borrachas, madeiras, vidros, porcelanas, pecas de máquinas, fios de cobre, sacos de estopa, borras oleosas, baterias e latas de metal.

Dentre os gases que se formaram ao passar dos anos tem-se o benzeno, causador de câncer, de várias formas de leucemia, afetando o funcionamento da medula óssea, potencializando anemias, causando sangramentos excessivos e recorrentes, causando danos ao sistema imunológico. Em casos mais graves, o gás benzeno pode causar infertilidade nas mulheres e efeitos devastadores nos fetos, como baixo peso, formação atrasada óssea e danos na medula óssea.

Outro gás de extrema periculosidade encontrado no terreno foi o gás decano, que possui uma densa e alta combustão, podendo se tornar anestésico se inalado em grandes e altas quantidades. Em casos mais graves e extremos pode causar até mesmo pneumonia química. Inclusive a justificativa dada para que ocorressem as explosões que vitimizaram dois funcionários do condomínio no dia 20 de abril de 2000, fora a liberação excessiva desse gás.

Diante do agravamento da situação, após tais descobertas, foi aplicado pela CETESB auto de infração de penalidade de advertência em face das empresas Cofap - Companhia Fabricadora de Peças, Administradora e Construtora Soma, SQG Empreendimentos Construções e Paulicoop Empreendimentos Imobiliários.

A CETESB ainda exigiu a apresentação de um Plano de Intervenção para remediação da área, as quais deveriam contemplar, isolada ou conjuntamente, a eliminação dos agentes causadores do risco, a eliminação das vias de exposição ou a remoção dos receptores.

Entretanto, diante da postura adotada pelos responsáveis legais em protelar a apresentação de um Plano de Intervenção que contemple a adoção de medidas destinadas à eliminação dos cenários de risco a que estão expostos os moradores, apontados pelos próprios estudos apresentados pela Cofap, avaliados tanto pela Agência Ambiental como pelo Instituto de Pesquisas Tecnológicas (IPT), e das incertezas associadas aos mesmos estudos, a CETESB entendeu ser necessária a remoção dos moradores de 11 edifícios do Conjunto Residencial, instalados em áreas prioritárias de risco do condomínio.

Diante desta decisão, comunicada oficialmente em 12/09/2011 às empresas responsáveis pela contaminação, à Prefeitura Municipal de Mauá e ao Ministério Público Estadual, a Cofap protocolou na sede da CETESB, um plano conceitual contemplando as medidas de intervenção a serem adotadas, tendo sido compromissado pela SQG e Paulicoop, que os moradores a serem eventualmente removidos para a execução das medidas de 
intervenção serão transferidos para edifícios a serem por elas finalizados ou construídos em áreas do conjunto residencial que não apresentem riscos para a ocupação.

O Condomínio Barão de Mauá, foi apelidado por seus vizinhos como “Chernobil”, em uma alusão ao acidente nuclear na usina ucraniana em 1986, que contaminou metade dos países europeus com emanações radioativas depois de uma explosão.

\section{O CASO NA COMISSÃO INTERAMERICANA DE DIREITOS HUMANOS}

Vale ressaltar que o caso ora analisado ainda não chegou na Corte Interamericana de Direitos Humanos, apesar de seu tramite perante a Comissão Interamericana de Direitos Humanos ter se findado e a própria Comissão concluir que é competente para examinar o mérito do caso, decidindo que a petição é admissível.

Todos os fatos e problemas enfrentados pelos moradores do Condomínio Barão de Mauá levaram a uma denúncia protocolada em 19 de setembro de 2005, por meio de petição contra a República Federativa do Brasil, alegando sua responsabilidade internacional pela violação dos artigos 1.1, 4, 5, 8 e 25 da Convenção Americana sobre Direitos Humanos, no que tange a situação relacionada a contaminação da área no Condomínio Barão de Mauá.

A referida denúncia alega que o Brasil é responsável direto pela degradação ambiental e pelo risco para a vida, integridade pessoal e a saúde decorrente da contaminação do solo e do consequente dano material em face dos moradores do Conjunto Habitacional "Barão de Mauá" e demais envolvidos nos eventos ocorridos por tal situação.

Em resposta a denúncia, tendo em vista notificação feita pela Comissão Interamericana de Direitos Humanos, o Estado Brasileira alega que a petição seria inadmissível, haja vista que os recursos internos não teriam sido esgotados, destacando a existência de uma ação civil pública pendente de julgamento, contra o Município de Mauá e as quatro empresas privadas envolvidas no caso.

Entretanto, a Comissão Interamericana decidiu que a petição é admissível com relação à presunção de afronta e violação aos artigos 4, 5.1, 8, 13, 21 e 25 da Convenção Americana de Direitos Humanos.

A Comissão Interamericana decidiu avaliar a denúncia contra o Brasil, apresentada em setembro de 2005. A Comissão reconheceu que há potenciais violações aos direitos humanos pelo Brasil no caso Barão de Mauá, em pelo menos seis artigos da Convenção Americana sobre os Direitos Humanos, que garantem desde o direto a vida até à propriedade privada.

Verifica-se uma afronta ao direito à vida (artigo 4), direito a integridade pessoal (artigo 
5), direito as garantias (artigo 8), artigo 21 (direito à propriedade privada), proteção judicial (artigo 25), todas da Convenção Americana.

Diante da decisão, a Comissão fixou prazo para que as partes apresentem informações adicionais sobre o caso, haja vista que o problema atinge aproximadamente 531 pessoas. A comissão ainda possibilitou a ampliação da lista de vítimas.

Na denúncia é declarado que o terreno onde se ergueu o Condomínio Habitacional Barão de Mauá, foi utilizado como depósito clandestino de lixo industrial desde 1973.

Assim, tanto o proprietário do terreno a época, Companhia Fabricadora de Peças COFAP, bem como a agência ambiental do Estado encarregada do controle, da licença, da supervisão e do monitoramento de atividades potencialmente poluidoras do meio ambiente, a Companhia de Tecnologia de Saneamento Ambiental - CETESB, tinham pleno conhecimento do despejo ilícito de material tóxico no local.

Outrossim, foi concedido a autorização pelas autoridades locais para que todas as empresas envolvidas no caso pudessem fazer a terraplanagem na área para fins de planejamento e construção do Condomínio, contrariando as leis internas existentes.

Tanto a CETESB, como alhures informado, órgão responsável pela fiscalização ambiental do local, como a municipalidade de Mauá emitiram autorização para que a construção se iniciasse, sem qualquer indício de problemas relacionados a contaminação ambiental do solo.

Aí estaria a grande falha do Estado brasileiro, pois apesar de todo o risco eminente com relação a contaminação do solo, não houve qualquer cuidado para que a construção do condomínio fosse barrada ou mesmo realizada de forma adequada. Pelo contrário, todas as autorizações governamentais foram expedidas e liberadas.

Ainda é mencionada na denúncia a morte de um dos trabalhadores da construção e a lesão corporal grave ocasionada em outro, ocorrida por conta dos gases gerados pela contaminação do solo.

Há ainda informações na denúncia, que após a descoberta da contaminação do solo, o Estado Brasileiro ocultou aos moradores do Condomínio informações fundamentais relativas à degradação do meio ambiente, bem como dos riscos que essa contaminação poderia causar aos moradores.

Aduz ainda que houve demora injustificada para se chegar a uma sentença final sobre os fatos denunciados, já que a investigação sobre os fatos já durava mais de 10 anos, desde a explosão que ocorrera no ano de 2000, mencionando ainda a demora também na tramitação da Ação Civil Pública proposta pelo Ministério Público.

Assim, o denunciante afirma que com relação aos recursos penais e civis 
disponibilizados pelo Estado Brasileiro houve demora injustificada para se chegar a um julgamento final.

Por outro lado, o Estado afirma que os recursos internos não foram esgotados, utilizando esse argumento como defesa em sua petição perante a Comissão Interamericana de Direitos Humanos.

De qualquer forma, a Comissão afastou as alegações do Estado Brasileiro, considerando que era competente para analisar o caso, afastando inclusive a alegação do Brasil com relação ao não esgotamento dos recursos internos, haja vista que segundo o Direito Internacional, se a legislação interna não oferece o devido processo judicial para a proteção do direito a ser tutelado, quando se nega à suposta vítima o acesso aos recursos da jurisdição interna ou ainda quando há demora injustificada na decisão sobre os recursos.

No mérito a Comissão, entendeu que as alegações são admissíveis nos termos do artigo 4 da Convenção Americana ${ }^{9}$, principalmente se considerar a explosão ocorrida dia 20 de abril de 2000, ocasionando a morte de uma pessoa, bem como lesão corporal grave em outra.

Afirma ainda que a presumida contaminação poder ter afetado o uso e gozo da propriedade das supostas vítimas de modo a constituir uma violação do artigo 21 da Convenção Americana. ${ }^{10}$

A Comissão Interamericana de Direitos Humanos entendeu ainda que poderiam se caracterizar violações aos artigos $5.1^{11}$ e $25^{12}$ da Convenção Americana.

\footnotetext{
9 Artigo $4^{\circ}$ - Direito à vida 1 . Toda pessoa tem o direito de que se respeite sua vida. Esse direito deve ser protegido pela lei e, em geral, desde o momento da concepção. Ninguém pode ser privado da vida arbitrariamente. 2. Nos países que não houverem abolido a pena de morte, esta só poderá ser imposta pelos delitos mais graves, em cumprimento de sentença final de tribunal competente e em conformidade com a lei que estabeleça tal pena, promulgada antes de haver o delito sido cometido. Tampouco se estenderá sua aplicação a delitos aos quais não se aplique atualmente. 3. Não se pode restabelecer a pena de morte nos Estados que a hajam abolido.4. Em nenhum caso pode a pena de morte ser aplicada a delitos políticos, nem a delitos comuns conexos com delitos políticos.5. Não se deve impor a pena de morte a pessoa que, no momento da perpetração do delito, for menor de dezoito anos, ou maior de setenta, nem aplicá-la a mulher em estado de gravidez.
}

10 Artigo 21 - Direito à propriedade privada1. Toda pessoa tem direito ao uso e gozo de seus bens. A lei pode subordinar esse uso e gozo ao interesse social. 2. Nenhuma pessoa pode ser privada de seus bens, salvo mediante o pagamento de indenização justa, por motivo de utilidade pública ou de interesse social e nos casos e na forma estabelecidos pela lei. 3. Tanto a usura, como qualquer outra forma de exploração do homem pelo homem, devem ser reprimidas pela lei.

${ }^{11}$ Artigo $5^{\circ}$ - Direito à integridade pessoal 1. Toda pessoa tem direito a que se respeite sua integridade física, psíquica e moral.

12 Artigo 25 - Proteção judicial 1. Toda pessoa tem direito a um recurso simples e rápido ou a qualquer outro recurso efetivo, perante os juízes ou tribunais competentes, que a proteja contra atos que violem seus direitos fundamentais reconhecidos pela Constituição, pela lei ou pela presente Convenção, mesmo quando tal violação seja cometida por pessoas que estejam atuando no exercício de suas funções oficiais. 2. Os Estados-partes comprometem-se: a) a assegurar que a autoridade competente prevista pelo sistema legal do Estado decida sobre 
Por fim a Comissão Interamericana alega que a presumida falta e/ou manipulação de informações sobre a degradação ambiental do terreno em que o Condomínio foi construído e sobre seus efeitos para a saúde e a vida das supostas vítimas poderiam caracterizar uma violação do artigo 13 da Convenção Americana ${ }^{13}$.

Desta feita, a Comissão Interamericana de Direitos Humanos, declarou que a petição de denúncia atendeu todos os requisitos de admissibilidade da Convenção Americana, admitindo a petição, notificando ambas as partes sobre a decisão, continuando sua análise do mérito do caso, bem como publicando a decisão no relatório anual à Assembleia Geral da Organização dos Estados Americanos.

\section{CONCLUSÃO}

Pode se afirmar que o Brasil não se manteve indiferente ao processo de internacionalização do Direito, pelo contrário, levou a efeito alterações na Constituição da República para permitir uma maior penetração do direito internacional no direito interno, bem como uma maior proteção aos direitos humanos.

A maior proteção dos direitos humanos se fez sentir tanto ao se conferir status constitucional aos tratados de direitos humanos aprovados na forma do $\S 3^{\circ}$ do art. $5^{\circ}$, ou seja, com quórum qualificado de três quintos, como na posição adotada pelo Supremo Tribunal Federal que outorgou status de norma supralegal aos tratados de direitos humanos anteriores a data da promulgação da Emenda à Constituição n. 45/04.

\footnotetext{
os direitos de toda pessoa que interpuser tal recurso; b) a desenvolver as possibilidades de recurso judicial; e c) a assegurar o cumprimento, pelas autoridades competentes, de toda decisão em que se tenha considerado procedente o recurso.

${ }^{13}$ Artigo 13 - Liberdade de pensamento e de expressão 1 . Toda pessoa tem o direito à liberdade de pensamento e de expressão. Esse direito inclui a liberdade de procurar, receber e difundir informações e idéias de qualquer natureza, sem considerações de fronteiras, verbalmente ou por escrito, ou em forma impressa ou artística, ou por qualquer meio de sua escolha. 2. O exercício do direito previsto no inciso precedente não pode estar sujeito à censura prévia, mas a responsabilidades ulteriores, que devem ser expressamente previstas em lei e que se façam necessárias para assegurar: a) o respeito dos direitos e da reputação das demais pessoas; b) a proteção da segurança nacional, da ordem pública, ou da saúde ou da moral públicas. 3. Não se pode restringir o direito de expressão por vias e meios indiretos, tais como o abuso de controles oficiais ou particulares de papel de imprensa, de frequências radioelétricas ou de equipamentos e aparelhos usados na difusão de informação, nem por quaisquer outros meios destinados a obstar a comunicação e a circulação de idéias e opiniões. 4. A lei pode submeter os espetáculos públicos a censura prévia, com o objetivo exclusivo de regular o acesso a eles, para proteção moral da infância e da adolescência, sem prejuízo do disposto no inciso 2. 5. A lei deve proibir toda propaganda a favor da guerra, bem como toda apologia ao ódio nacional, racial ou religioso que constitua incitamento à discriminação, à hostilidade, ao crime ou à violência.
} 
Nesse contexto, verifica-se o Pacto de São José da Costa Rica passou a usufruir no ordenamento jurídico de um status normativo diferenciado das demais leis ordinárias, portanto, detentor de maior efetividade e aplicabilidade.

No caso do Condomínio Barão de Mauá, em que a denúncia foi aceita pela Comissão Interamericana de Direitos Humanos, verificou-se que o sistema interamericano de direitos humanos se mostrou mais efetivo na proteção dos direitos humanos do que o ordenamento jurídico brasileiro.

De outra parte, se viu a ação desastrosa do Estado Brasileiro, juntamente com empresas, inclusive uma delas transnacionais, ao emitir as autorizações de construção do Condomínio Barão de Mauá em uma área de alta contaminação, ferindo frontalmente vários artigos da Convenção Americana de Direitos Humanos.

Verifica-se uma análise mais profunda na decisão de admissibilidade da denúncia, ocasião que ponto a ponto foi discutido pela Comissão, até se chegar a decisão final que admitiu a denúncia.

Ademais, os interesses das empresas, principalmente aquelas transnacionais, mais uma vez superaram os interesses sociais, ao passo que o Estado Brasileiro de alguma forma se sucumbiu aos pedidos das empresas, ao não se realizar uma fiscalização efetiva e adequada na construção do Condomínio, autorizando sua construção sobre área completamente contaminada.

O fato é que os Direitos Humanos não podem ser superados por interesses particulares e o Estado deve sempre agir nesse sentido, pois deve cuidar para o cumprimento do que realmente é interessante a população.

\section{REFERÊNCIAS}

ADVOCACIA GERAL DA UNIÃO: Disponível em http://www.agu.gov.br. Acesso em 13.06.2015;

BARBOSA, Rui. Oração aos moços. São Paulo: Editora Martin Claret. 2003.

BOBBIO, Norberto. A era do direito. Tradução de Carlos Nelson Coutinho. Rio de Janeiro: Elsevier, 2004.

CANÇADO TRINDADE, Antônio Augusto (Editor) A Proteção dos Direitos Humanos nos 
Planos Nacional e Internacional: Perspectivas Brasileiras $1^{\text {a }}$ ed, San José de Costa Rica: Friedrich Naumann - Stiftung, 1992

, Antônio Augusto. A Proteção Internacional dos Direitos Humanos:

Fundamentos Jurídicos e Instrumentos Básicos 1a ed. São Paulo: Editora Saraiva, 1991.

COMPARATO, Fabio Konder. Afirmação histórica dos Direitos Humanos. São Paulo: Saraiva, $3^{\circ}$ ed. 2003.

CORTE INTERNACIONAL DE DIREITOS HUMANOS: Disponível em http://www.corteidh.or.cr/docs/casos/articulos/seriec_149_por.pdf >acesso em 31/05/2015;

CUNHA, Paulo Ferreira da. A Constituição Viva - Cidadania e Direitos Humanos. Porto Alegre: Ed. Livraria do Advogado, 2007.

DALLARI, Adilson de Abreu. Elementos de Teoria Geral do Estado. São Paulo: Saraivam $16^{\circ}$ ed., 1991.

DELMAS- MARTY, Mireille. Três desafios para um direito mundial. Rio de Janeiro: Lumen Iures, tradução Fauzi Hassan Choukr, 2003.

FERREIRA FILHO, Manoel Gonçalves. Direitos Humanos Fundamentais. $8^{a}$ ed. São Paulo: Ed. Saraiva, 2006.

FEUILLADE, Milton C. El Deber de Investigar, en la Jurisprudencia de la Corte Interamericana de Derechos Humanos. Revista Mestrado em Direito. Direitos Humanos Fundamentais. Vol. 10, n. $2, \quad 2010, \quad$ p. $16 . \quad$ Disponível em: http://intranet.unifieo.br/legado/edifieo/index.php/rmd/article/view/453/496. Acesso em: 20 Fev. 2011.

HÄBERLE, Peter. Estado Constitucional Cooperativo, tradução do original em alemão por Marcos Augusto Maliska e Elisete Antoniuk. Rio de Janeiro: Renovar, 2007. 
LAFER, Celso. A reconstrução dos Direitos humanos. São Paulo: Companhia das Letras, 2006.

, Celso. A Internacionalização dos Direitos Humanos. Constituição, Racismo e Relações Internacionais. São Paulo: Manole, 2005.

- A proteção dos direitos humanos no Mercosul. In:

PIOVESAN, Flávia (Coord.). Direitos humanos, globalização econômica e integração regional: desafios ao direito constitucional internacional. São Paulo: Max Limonad, 2002.

LEWANDOWSKI, Enrique Ricardo. Proteção dos Direitos Humanos na Ordem Interna e Internacional. Rio de Janeiro: Forense, 1984.

MAUES, Antonio Moreira, "Supralegalidade dos tratados internacionais de direitos humanos e interpretação constitucional In. A eficácia nacional e internacional dos direitos humanos. Coordenadores: MAUES, Antonio Moreira; LOPES, Ana Maria D’Avila. Rio de Janeiro: Lumen Juris, 2013.

MARTINS, Ana Maria Guerra. Direito Internacional dos Direitos Humanos, Coimbra: Almedina, 2206

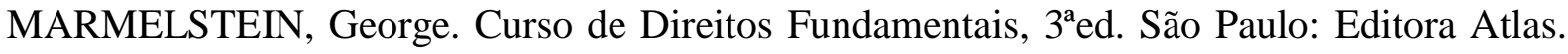
2011;

MAZZUOLI, Valério de Oliveira. Direitos Humanos \& Relações Internacionais. Campinas: Agá Juris Editoria, 2010;

MENDES, Gilmar Ferreira. Os direitos fundamentais e seus múltiplos significados na ordem constitucional. Revista Diálogo Jurídico, Salvador, CAJ - Centro de Atualização Jurídica, nº 10, janeiro, 2002. Disponível na Internet: 〈http://www.direitopublico.com.br>. Acesso em: $31 / 05 / 2015$;

PIOVESAN, Flavia. Direitos Humanos e o Direito Constitucional Internacional. São Paulo: Max Limonad, 1996. 
REZEK, Francisco. Direito Internacional. São Paulo: Saraiva, 12ºd., 2010.

SANTOS, Boaventura de Souza. A construção multicultural da igualdade e da diferença. Coimbra: CES, 1999.

SARLET, Wolfgang Sarlet. A Eficácia dos Direitos Fundamentais. Porto Alegre: Livraria do Advogado, 2003.

SILVEIRA, Vladmir Oliveira da (coord.); CAMPELLO, Livia Gaigher Bósio (org.). Estudos e Debates em Direitos Humanos. Vol. II. São Paulo: Letras Jurídicas, 2012;

SILVEIRA, Vladmir Oliveira da, ROCASOLANO, Maria Mendez. Direitos Humanos: Conceitos, Significados e Funções. São Paulo: Saraiva, 2010;

SILVEIRA, Vladmir Oliveira da (Org.), PERES, Viviane M. da S. Martins, PERES, A Martins. Estudos e Debates em Direitos Humanos. Florianópolis: Conceito Editoria, 2010;

SOUZA SANTOS, Boaventura. Por uma Concepção Multicultural de Direitos Humanos. In: Reconhecer para Libertar: os caminhos do cosmopolitanismo multicultural. Rio de Janeiro: Civilização Brasileira, 2003.

VON IHERING, Rudolf. A luta pelo direito. 12 ed. Rio de Janeiro: Forense, 1992.

WEISS, Carlos. Direitos Humanos Contemporâneos. $2^{\circ}$ ed. São Paulo: Malheiros Editores. 2010 . 